ORIGINAL ARTICLE

\title{
The effect of music and vagus nerve to improve various Diseases
}

\author{
ATIYEH SADAT HASANI HELM ${ }^{1}$, MAHDI RAMEZANI ${ }^{*}$ \\ ${ }^{1}$ Department of Occupational Therapy, School of Rehabilitation, Hamadan university of Medical Sciences, Hamadan, IRAN. \\ ${ }^{2}$ Department of Anatomy, School of Medicine, Hamadan university of Medical Sciences, Hamadan, IRAN. \\ * Corresponding Author at : Department of Anatomy, School of Medicine, Hamadan university of Medical Sciences, Hamadan , IRAN. \\ Email:m.ramezani@umsha.ac.ir
}

\begin{abstract}
Human body has energy which determines you are sick, tired, bored, excited and angry or not. According to Physics music is placed in energy spectrum as one part of sounds and volumes, which can affect our body energy. On the other side the rhythmical and compositionality feature of music reinforces this consequence, due to these features, music is more populare than the other hobbies. We often use music in our daily lives, for example, from ringing the doorbell to using the phone or waiting in the elevator to reach the desired floor and etc. it is one common and available supplementary that human can use it for treating different diseases. The music plays an important role in activation of parasympathetic part via the vagus nerve stimulation. The vagus nerve is a tenth nerve of twelve cerebral nerves. The tenth nerve is one of the most important nerves which originates from the brain and is responsible for innervating face, thorax, abdomen and etc. It is a motor sensory nerve. The vagus nerve is also involved in the parasympathetic system. This nerve has two sensory ganglia that transmit sensory impulses: the superior and the inferior ganglia, by which we can affect parasympathetic Nervous System for improvement. Generally these ganglions innervates different part of body such as: ear (where the most stimulations happen in this place), larynx, heart, pulmonary system, abdomen and abdominal viscera. Because of this innervation vagus nerve stimulation can change the activity of pulmonary system, heart, abdomen, intestine and etc. The music stimulates the vagus receptors of the ear.

The goal of this article is review the music effects on vagus nerve for treating some diseases such as gut problems, mental health disorders, heart problems, epilepsy, seizures and etc. Finally, since music is always accessible and the human body utilizes it on a daily basis, we can use music as a complementary method in occupational therapy.
\end{abstract}

Keywords: Music therapy, Vagus nerve stimulation, Occupational therapy, complementary therapy.

\section{INTRODUCTION}

Music Is an organized combination which is different in some items with sound such as: intensity, rhythm, and pitch[1]. Music can change our emotions, thought and feelings[2]. Muic is used in different areas as follows:

1- Patient with orthopedic surgery, some positive effects such as reducing nausea, anxiety and pain and improving mood on people who have had orthopedic surgery through receiving their Music Therapy (MT) sessions [3].

2-Autism Spectrum disorder (ASD), ASD is an umbrella term for several disorders such as: autism, asperger, pervasive developmental disorder, disintegrative disorder which are brain and developmental disorders and related to society and communication difficulties[4], music improves ASD's skills, like: initiating behavior, social interaction, verbal and nonverbal communication and emotional aspects [5].

Music therapy is a unique, safe, structured treatment which it can engage ASD children in joyful interaction with others. The majority of children respond positively to music. Music therapy evokes them for social engagement and practice of social skills. In therapy sessions they are included to be active (singing or playing the instruments) or passive (just listening). Even in adults with ASD music therapy is effective. Music therapists develop music-based interventions that facilitate communication, social, motor, sensory, emotional, cognitive, and musical skills. Music therapy services are customized to the individual's priorities and abilities, and these services can be provided with the participation of families and treatment teams. People from different socioeconomic backgrounds, cultures and ages can be included in music therapy Music therapy may even be offered in schools, homes, music therapy clinics or hospitals. Music therapy can leads to joint attention and also help boost nonverbal communication skills in therapy procedure and socioemotional reciprocity. In addition, music therapy may help enhance social adaptation in children with ASD and improve parent-child relationships. Music cues can be used to increase patience and waiting for the turn to come during a social experience, with music structure outlining the social response time of the peer. Musical cues can teach children with ASD to wait and control motivations during a social experience, with a musical structure that designs peer-to-peer response time [6], [7].

3- Dementia, dementia is a progressive cognitive disturbance leading to reduction in independent function [8]. Music therapy also reveals its efficacy in people with dementia, which it can alter behavioral, psychological and cognitive features in Alzheimer disease [9].

4- Depression, depression is a mood disorder consist of reduction in interests and loss of enjoyment [10]. Researches point to a persistent and remarkable reduction in depression symptoms and improvement in the quality of life via MT [11].

The purpose of this article is to further investigate and focus on the role of music in the human body system. Music affects the physiological, mental and physical dimensions of human beings [12], [13].

According to previous articles, music affects the body by stimulating the vagus nerve (VNS) [14]. Using VNS, we can achieve positive states from different aspects. We have different methods to stimulate it in cases where the vagus 
nerve (VN) has sensory fibers such as the ear, larynx, etc. [15]. Unfortunately, little research has been done on how music affects the vagus nerve, and more is suggested [16].

\section{VAGUS NERVE}

Vagus nerve or Vagal Nerve (VN) is the tenth nerve of the cranial nerves (CNX) [15]. In addition, it was historically called Pneumogastric nerve, which is responsible for your good feeling, sufficient communication and optimal state of the body and the gut[17], [18], [19]. Anatomically, VN is an afferent (3/4 of fibers) an efferent (1/4 of fibers) nerve [15, 19]. The afferent component innervates tympanic membrane, infrantentorial dura, external ear and external auditory meatus, pharynx, larynx, trachea, esophagus and abdominal viscera. It also innervates the taste receptors in the epiglottic area. On the other side, the efferent component is the responsible for innervating the pharyngeal muscles of larynx and pharynx, muscle of the upper esophagus, the muscle of the uvula, palatoglossus muscle and the levator veli palatini. Additionally, VN with its preganglionic parasympathetic neurons located in the dorsal motor nucleus of medulla play an important roll in innervating the viscera of the neck and thoracic ( like heart) and abdomen[15].

When we cut the medulla in the transverse section (at the mid olivary level), 4 nuclei can be seen that correspond to VN. The following are: Solitarius, dorsal vagal, ambiguous and trigeminal. According to these cores, we have 4 main branches for $\mathrm{VN}$ in this section [12].

CNX with its dorsal nucleus plays an important role in parasympathetic components. One of these CNX nerves, which rises from the dorsal vagal nucleus to participate in the fight against the autonomic nervous system (ANS), is divided into two branches through the esophageal canal, one for the right side of the body and The other is for the left, the left gives the heart more nerve than the viscera. The right side connects the sinus node to the heartbeat, the arm tree, the stomach, the small intestine, and the large intestine [20], [12].

Finally, where only the peripheral branch of the $\mathrm{VN}$ is sent is the external ear, the auricular VN, also called the Arnold or Alderman nerve. The auricular VN (AVN), also called the Arnold or Alderman nerve, is the only peripheral branch of the $\mathrm{VN}$ that is sent to the external ear. It is afferent and has the most receptors in the ear, the central concha and other areas of the ear such as anti-helix, tragus, etc. have some receptors but their receptors are not equal to pinna [21].

In the ear, addition to the AVN receptors, we have some receptors that are related to other nerves, such as the auriculotemporal nerve, the great ear nerve [21], the sensory branch of the cervical network that innervates the sensation of the lower part of the external auditory canal [22] and the small occipital nerve [21], which originates in the cervical network and is responsible for feeling the upper and inner third of the canal [22]. Another nerve next to the AVN is the facial nerve, which has both motor and sensory fibers, one of which is the parasympathetic nerves, and in addition to its sensory nerve, innervates the taste of the tongue, the external auditory ear, the tympanic membrane, and the ear bone [23], [24]. Maybe this is what can change our imitations with different types of music [21]. Activating the sympathetic for a longer period of time leads to an energy imbalance in our body and the system cannot provide enough energy, which can lead to premature aging and disease and eventually death [16]. When the vagus afferent nerve is activated, it leads to sympathetic activation [21].

\section{vagus nerve stimulation (vns)}

The term VNS consists of all techniques that stimulate vagus nerve [19]. VNS affects on diseases including: autonomic neuropathy, chronic pain disease, neurodegenerative alignment, inflammation and cardiovascular disease, mental disorders, neuro developmental disorder, autoimmune disease, vasovagal syncope, hyperhidrosis, tachycardi syndrome, metabolic alignment [16], [19], [25]. Some non-invasive methods to VNS are: stress reduction, Nutrition, exercise, music for instance, music with high amplitude and low frequency is one of the ways to stimulate the tenth pair of cerebral nerves. This type of music has a great effect on depression [19], micro organism [12] and transcutaneous VNS (tVNS), which is performed by stimulating the auditory nerve branch of the vagus nerve in the skin of the ear. As a result of Tiantian Jia et al.'s work, tVNS can dicrease heart rate variability (HRV) and be effective in reducing sympathetic neural flow, which is desirable in conditions characterized by increased sympathetic nerve activity such as heart failure. It can affect human physiology and provide a simple and inexpensive option for an invasive VNS [26].

\section{music and vagus nerve}

ANS has two divisions, one of them is sympathetic nervous system and the other is parasympathetic nervous system which is more focused on in this section. The motor components of PNS are performed in the cranial nerves III, VII, IX and X and in the sacral nerves.

The responsibility of autonomic nervous system is regulating the body's unconscious actions. The parasympathetic system is responsible for stimulation of "rest-and-digest" or "feed and breed"[3] activities and this action is described as being complementary to that of the sympathetic nervous system, which is responsible for stimulating activities related to fight-or-flight response. Some PNS responsibilities are construction of pupils (miosis), decreased heart rate and blood pressure, constriction of bronchial muscles, lacrimation changes, increase in digestion, increased production of saliva and mucus, increase in urine secretion.

Music stimulates the vagus nerve, which in turn stimulates the ANS system via VNS and relaxes the body, it means music activates the PNS and have prominent roll in relaxation because of decrease heart rate, blood pressure, respiration rate, increase motility and relaxation of sphincters, Increase insulin and digestive enzymes (it can solve some gut problems), contraction of kidneys muscles, contraction of bladder muscles (more activation of kidneys and bladder) and relaxation of internal sphincter that aids to urination[14], [16], [25], [22], [27].

\section{music therapy}

Music therapy is the clinical and executive interventions which the goal of it is achieving to individualized purpose and target. MT is performed by a reputable specialist who has undergone a music therapy program and gained knowledge and expertise in his or her work. 
Music therapy helps increase social adaptation skills in children with ASD and improves the quality of parentchild relationships. Music cues can be used to assist with waiting, impulse control during a social experience, with music structure outlining the social response time of the peer. Musical cues can teach children with ASD to wait and control motivations during a social experience, with a musical structure [6].

In addition MT affect on depression. Both MT, active and receptive (passive) is effective in the treatment of depression because active MT in the context of therapy offers new aesthetic, physical and relational opportunities to the patient. On the other hand just listening to music or receptive MT reduces symptoms of depression in adults. Receptive MT over period of time can lead to reduce depressive symptoms in the adult population. MT also decrease anxiety and improve function of depressed people. We can also number singing as one part of active MT which improves symptoms of depression. In patients, choir participation improved exhilaration, overall mental health, anxiety, and quality of life. These interventions are even useful for enhancing mental health in older people and improving self-esteem and wellbeing in pregnant mothers [28], [29], [30].

MT is also effective in improving dementia. While receptive MT decreases agitation, anxiety, stress and behavioral problems in the elderly and it is more effective than active MT, singing, a subset of music therapy, improves wellbeing, quality of life and cognition and reduce pain. The function of verbal memory remains constant over time in the singing group. Furthermore, singing changes attitude and develope meaningful social connections. In addition, a person with dementia experiences the meaningful social connections as one part of community member. Beside of music effect on diseases, music improves sleep quality. It can lead to better sleep quality in older adults in different aspects of sleep, i.e. longer sleep duration, more sleep efficiency, shorter sleep delay, less sleep disturbance and less daily dysfunction. Music affect on student's sleep and procedure and significantly improve it. It is also effective in homeless women that sleep in shelters [29], [30], [31], [32], [33], [34].

\section{CONCLUSION}

All beings produce, have, send and receive the energy from different sources. Energy makes human alert and defines whether you are sick or not. Music is one of energy that is utilized daily, consciously or unconsciously.

It appears clear that the use of music as a therapeutic tool is very useful in a number of different mental health conditions and in promoting general mental wellbeing. This is particularly true when music is an adjunct for treating depression, anxiety, schizophrenia, and also dementia. Music appears to be beneficial to both the individual, and also to the improvement of social cohesion. The reasons for this must reside in the nature of music itself as an art form which supports human interactions within society.

Depending on the characteristics of the music such as rhythm, frequency, amplitude, etc., different types of music affect the PNS which is responsible for energy building, food digestion, and assimilation. Light music for PNS has calming answers and calms the human being, while high- energy music like rock has reverse responses for the body. Music allows us to improve aggression, reduce muscle tone and treat constipation through the VNS process and PNS.

Generally music can stimulates $\mathrm{VN}$ and by this function affects on PNS activation. Because of this music feature, we can utilize it for some diseases which require to lower vagal tone for recovery.

\section{REFERENCES}

[1]. Olsen N K, Dean R T, Leung Y. What Constitutes a Phrase in Sound-Based Music?. PLoS One. 2016 Dec 20;11(12):e0167643.

[2]. Molnar-Szakacs I, Heaton P. Music: a unique window into the world of autism. Annals of the New York Academy of Sciences. 2012 Apr; 1252:318-24.

[3]. Gallagher L M, Gardner V, Bates D, Mason S, Nemecek, J, DiFiore J B and et all. Impact of Music Therapy on Hospitalized Patients Post-Elective Orthopaedic Surgery: A Randomized Controlled Trial. Orthopedic nursing. Mar/Apr 2018; 37(2):124-133.

[4]. Sanchack K E,Thomas C A. Autism Spectrum Disorder: Primary Care Principles. American family physician. 2016 Dec 15; 94(12):972-979.

[5]. Geretsegger M, Elefant C, Mössler K A, Gold C. Music therapy for people with autism spectrum disorder. The Cochrane database of systematic reviews. 2014 Jun 17; 2014(6):CD004381.

[6]. LaGasse A B. Social outcomes in children with autism spectrum disorder: a review of music therapy outcomes. Patient related outcome measures. 2017 Feb 20; 8:23-32.

[7]. Geretsegger M, Elefant C, Mössler K A, Gold C. Music therapy for people with autism spectrum disorder. The Cochrane database of systematic reviews. 2014 Jun 17; 2014(6):CD004381.

[8]. Gale S A, Acar D, Daffner K R. Dementia. The American journal of medicine. 2018 Oct; 131(10):1161-1169.

[9]. Gómez Gallego, M, Gómez García J. Music therapy and Alzheimer's disease: Cognitive, psychological, and behavioural effects. Musicoterapia en la enfermedad de Alzheimer: efectos cognitivos, psicológicos y conductuales. Neurologia (Barcelona, Spain). 2017 Jun; 32(5):300-308.

[10]. Aalbers S, Fusar-Poli L, Freeman R E, Spreen M, Ket J C, Vink A C and et all. Music therapy for depression. The Cochrane database of systematic reviews. 2017 Nov 16; 11(11):CD004517.

[11]. Van Assche, E, De Backer J, Vermote R. (2015). Muziektherapie bij depressie [Music therapy and depression]. Tijdschrift voor psychiatrie. 2015; 57(11):823-9

[12]. Forsythe P, Bienenstock J. Kunze W A. Vagal pathways for microbiome-brain-gut axis communication. Advances in experimental medicine and biology.2014; 817: 115-133

[13]. Kaniusas E, Kampusch S, Tittgemeyer M, Panetsos F, Gines R F, Papa M and et all. Current Directions in the Auricular Vagus Nerve Stimulation I - A Physiological Perspective. Frontiers in neuroscience. 2019 Aug 9; 13:854.

[14]. Yuen A W, Sander J W. Can natural ways to stimulate the vagus nerve improve seizure control. Epilepsy \& behavior. 2017; 67: 105-110.

[15]. Fix J. High-Yield Neuroanatomy. USA: Lippincott Williams and Wilkins; 2005

[16]. Ellis R, Thayer F. Music and Autonomic Nervous System (Dys) function. Music Percept. 2010; 27(4): 317-326.

[17]. Zimmerman E. I Now Suspect the Vagus Nerve Is the Key to Well-being. New York; May 9, 2019. Available from: https://www.google.com/amp/s/www.thecut.com/amp/2019/0 5/i-now-suspect-the-vagus-nerve-is-the-key-to-wellbeing.html 
[18]. Fix J. Neuroanatomy. India: Lippincott Williams and Wilkins; 2008.

[19]. Howland R H. Vagus Nerve Stimulation. Current behavioral neuroscience reports.2014; 1(2): 64-73.

[20]. Fix J. Neuroanatomy. India: Lippincott Williams and Wilkins; 2008.

[21]. Eugenijus K, Stefan K, Marc T, Fivos P, Fernandez G, Michele $P$, et al. Current Directions in the Auricular Vagus Nerve Stimulation I - A Physiological Perspective. Frontiers in Neuroscience.2019;13:854.

[22]. Weinzweig J. Plastic Surgery Secrets Plus E-Book. Philadelphia: Elsevier Health Sciences, 2010.

[23]. Cesmebasi A. Anatomy of the Cervical Plexus and Its Branches in: Tubbs R, Rizk E, Shoja M, Loukas M, Barbaro $\mathrm{N}$, Spinner R, editors. Nerves and Nerve Injuries. Academic Press:2015; 441-449.

[24]. Dulak D, Naqvi IA. Neuroanatomy, Cranial Nerve 7 (Facial). StatPearls Publishing.Treasure Island (Florida); 2020 Jan. Available https://www.ncbi.nlm.nih.gov/books/NBK526119/

[25]. Clancy J, Mary D, Witte K, Greenwood J, Deuchars A, Deuchars J. Non-invasive Vagus Nerve Stimulation in Healthy Humans Reduces Sympathetic Nerve Activity. Brain Stimulation.2014; 6(7): 871-877.

[26]. Jia T, Ogawa $Y$, Miura $M$, Ito O, Kohzuki M. Music Attenuated a Decrease in Parasympathetic Nervous System Activity after Exercise. PloS one. 2016 Feb 3; 11(2):e0148648.

[27]. McCorry L K. Physiology of the autonomic nervous system. American journal of pharmaceutical education. 2007 Aug 15; 71(4):78.
[28]. Chan MF, Chan EA, Mok E, Kwan Tse FY. Effect of music on depression levels and physiological responses in community-based older adults Int J Ment Health Nurs. 2009; 18:285-94.

[29]. Wang S, Agius M. The use of Music Therapy in the treatment of Mental IIIness and the enhancement of Societal Wellbeing. Psychiatria Danubina. 2018 Nov;30 (Suppl 7):595-600.

[30]. Cooke ML, Moyle W, Shum DH, Harrison SD, Murfield JE. A randomized controlled trial exploring the effect of music on agitated behaviours and anxiety in older people with dementia. Aging Ment Health 2010; 14:905-16.

[31]. Lai HL, Good M. Music improves sleep quality in older adults. J Adv Nurs 2005; 49:234-44.

[32]. Pongan E, Tillmann B, Leveque Y, Trombert B, Getenet JC, Auguste N, Dauphinot V, El Haouari H, Navez M, Dorey JM, Krolak-Salmon P, Laurent B, Rouch I; LAC Mé Group. Can Musical or Painting Interventions Improve Chronic Pain, Mood, Quality of Life, and Cognition in Patients with Mild Alzheimer's Disease? Evidence from a Randomized Controlled Trial. J Alzheimers Dis 2017; 60:663-677.

[33]. Hernández-Ruiz E. Effect of music therapy on the anxiety levels and sleep patterns of abused women in shelters. J Music Ther 2005; 42:140-58.

[34]. Reagon C, Gale N, Enright S, Mann M, van Deursen R: A mixed-method systematic review to investigate the effect of group singing on health related quality of life, Reagon $C$, Gale N, Enright S, Mann M, van Deursen R, Complement Ther Med 2016; 27:1-11. 